\title{
Candidatos jóvenes en las elecciones generales de Ecuador: Evolución en el último quindenio
}

\section{Young candidates in the general elections in Ecuador: Evolution in the last fifteen years}

\author{
Oscar Rolando Sánchez López y José Eduardo Correa Calderón
}

Recepción: 30 de junio de 2017

Aceptación: 28 de agosto de 2017

\begin{abstract}
Resumen
El artículo presenta un estudio inédito en materia electoral, al menos en el Ecuador, que observa y analiza la participación de las y los jóvenes como candidatos en su búsqueda de ejercer el derecho a ser elegidos en los procesos electorales de los últimos quince años, para establecer la incidencia de los cambios constitucionales del año 2008, mediante la comparación de las condiciones del antes y después de la Constitución de Montecristi. Se utilizaron los datos oficiales proporcionados por el Consejo Nacional Electoral para realizar un análisis estadístico y exponer la situación real de los jóvenes, verificándose una marcada tendencia de relegar su participación a las suplencias o, cuando fueron candidatos principales, muy pocas veces ocuparon los primeros puestos, lo que ocasionó que, incluso en esa condición, pocas veces resultaron electos. Además, en una necesaria revisión de género, se constató que las mujeres pierden oportunidades electorales en la medida que avanzan en su edad y, en esa misma línea, los hombres - por el contrario - las ganan fundamentalmente en espacios protagónicos, seguramente como consecuencia de una cultura política "machista" que sigue vigente en el ámbito político.

Palabras clave: jóvenes, participación, elecciones, derechos.

\section{Abstract}

This article presents an unpublished study on electoral matters, at least in Ecuador, which observes and analyzes the participation of young people as candidates in their quest to exercise the right to be elected in the electoral processes of the last fifteen Years, to establish the impact of the constitutional changes of 2008, by comparing the conditions before and after the Constitution of Montecristi. Official data provided by the National Electoral Council were used to carry out a statistical analysis and to explain the real situation of the young people, with a marked tendency to relegate their participation to the substitutions or, when they were major candidates, they rarely occupied the top positions, Which caused that, even in that condition, seldom they were elected. In addition, in a necessary gender review, it was found that women lose electoral opportunities as they advance in their age and, in the same line, men - on the contrary - gain them mainly in leading spaces, probably as a consequence of "male chauvinist" political culture that is still in force in the political arena.
\end{abstract}

Keywords: youth, participation, elections, rights. 


\section{Introducción}

1 presente trabajo de investigación expone un análisis del derecho a ser elegido al que han tenido acceso los jóvenes desde una perspectiva evolutiva en los últimos 15 años. Partimos de la idea de que "la democracia, más allá de un régimen o forma de gobierno, es una forma de vida en donde se ponen de relieve los valores más altos en el sentido humano" (Jiménez-Morales, 2015: 36), pero de la que han sido excluidos los jóvenes. De hecho, en un estudio se afirmó que si bien "este tema no ha sido explorado en ningún foro... resulta pertinente al observar que la situación de desigualdad en que se encontraban las mujeres antes de las reformas que establecieron las cuotas, es parecida a la situación de los jóvenes" (AguilarLópez, 2013: 107).

Latinoamérica ha dado importantes muestras de innovación en su búsqueda por garantizar el ejercicio pleno de los derechos constitucionales, y los asuntos de participación no se han quedado atrás, ya que, por ejemplo, se comenzó a discutir acerca de la democracia desde nuevas concepciones como la democracia intercultural que busca la inclusión de los sectores indígenas en Bolivia (Mayorga, 2017), sin embargo que, al final del día, en el tema de jóvenes "la mayoría de estudios coinciden en que el nivel de participación es menor" (Rico-Revelo, 2013: 102). Esto hace necesario que las instituciones democráticas "reencanten a las personas jóvenes, incorporando nuevas dimensiones como la de género, cultura, ecología, como parte del diseño de políticas públicas, como en la necesidad de respetar las acciones de carácter autónomo y las nuevas configuraciones de la acción política" (Bivort, Martínez-Labrín, Orellana, \& Farías, 2016: 35).

Ahora bien, desde el 20 de octubre de 2008 los ecuatorianos y ecuatorianas que tengan 30 años de edad pueden candidatizarse a la Presidencia de la República, y, con 18 años para Asambleístas, según lo determinan los artículos 119 y 142 de la Constitución de la República del Ecuador; disminuyendo el requisito de edad, en el primer caso, en cinco años y, en el segundo, en siete, respecto a lo que establecía la Constitución de 1998, lo que, en teoría, permite el acceso de jóvenes a la gestión del poder público, reconociendo que tienen capacidad intelectual y derecho para participar de 
la contienda electoral; sin embargo, es importante estudiar la evolución del derecho a ser elegido en el constitucionalismo ecuatoriano y la variable de participación política de las y los jóvenes en las elecciones generales, es decir, presidenciales y legislativas.

En este punto, resulta necesario hacer un paréntesis para aclarar que "cuando referimos a los jóvenes no los comprendemos desde una categoría meramente biológica, sino que se alude a una condición histórica que se construye socioculturalmente" (Saez, 2017: 5), ya que "el planteo de los autodenominados 'jóvenes' introduce un horizonte heterogéneo de discursos y prácticas en la arena política, estableciendo continuidades, redefiniciones y rupturas con respecto a la generación anterior de activistas" (Kropff, 2011: 85). En ese mismo discurso, no debemos olvidar que "las juventudes comenzaron a ser definidas, más que por condiciones naturales, como construcciones sociales apoyadas en significaciones complejas afectadas por las condiciones históricas, psicobiológicas, la situación socioeconómica, las relaciones de género, las pautas culturales, etc." (Wahren, 2016). En todo caso, los puntos de referencia se los encuentra en la Convención Iberoamericana de Derechos de los Jóvenes - 18 a 35 años - y en la Ley de la Juventud - 18 a 29 años -, a lo que se agrega la percepción política cultural de quienes constituyen la población de candidatos jóvenes, en la que incluso se considera en ese grupo a políticos y políticas que tienen 35 a 40 años, con lo que determinamos, para los fines de esta investigación, dos grupos etarios juveniles comprendidos entre: $\operatorname{los} 18$ a 25 años y 26 a 35 años.

En ese sentido, uno de los objetivos propuestos es determinar el impacto material del desarrollo constitucional, en cuanto a derechos electorales, haciendo una evaluación del ejercicio del derecho constitucional a ser elegido de las y los jóvenes en el marco de las elecciones generales del último quindenio, que constituye un lapso de tiempo con cambios constitucionales significativos en ese aspecto, pues en el año 2008 se aprobó y entró en vigencia una nueva Constitución, cuyo artículo 61.1 determina que las ecuatorianas y los ecuatorianos tenemos derecho a "ser elegidos", es decir, a representar a la ciudadanía en espacios del poder público, respecto de lo cual debemos cuestionarnos cuántas personas tenemos la capacidad real para ejercerlo, en un mundo donde "la gente joven sigue siendo el grupo con menor 
disposición a votar" (Contreras-Aguirre \& Morales-Quiroga, 2014: 599).

En un estudio sobre Colombia se determinó que "son muchos los jóvenes que trabajan en campañas políticas, encargándose principalmente de repartir publicidad, o en labores logísticas y se sabe que votan con la perspectiva de que su candidato aprovisione empleo" (Durán-Sánchez, 2015: 54), lo que evidentemente amerita un análisis al caso, ya que las estadísticas siguen siendo desfavorables pese al avance tecnológico que engancha a los jóvenes, donde "el consumo de medios, específicamente la atención a contenidos en medios digitales, incrementa el desarrollo de la participación" (Leyva-Cordero, Muñiz, \& Flores Hernández, 2016: 68); al respecto, Ramírez Castro afirma que "contradecir la idea de que las nuevas tecnologías abren espacios para la democratización y para el desarrollo de la libertad de las nuevas generaciones, parece ser a todas luces una locura, pues es lógico pensar que la conectividad virtual genera espacios para la libertad de expresión y de debate" (Castro, 2014: 255), sin embargo, nuestro trabajo tratará de evidenciar si estos referentes provocaron algún cambio positivo respecto de la participación de jóvenes como candidatos.

En esta línea de ideas, si nos referimos al derecho a ser elegido eminentemente nos referimos también a los derechos de participación y a los derechos políticos, respecto de los cuales se dice que "estos derechos son universales, es decir, todos los seres humanos son sus titulares sin distinción de sexo, edad, raza, origen, cultura o ideología política, y su limitación sólo es permitida en casos especialísimos" (Reyes Kuri, 2009: 153); así por ejemplo, en un estudio realizado por el Centro de Estudios Constitucionales de Chile sobre los estándares interpretativos de la Corte Interamericana de Derechos Humanos en materia de derechos políticos y la inconvencionalidad de la ley brasileña de inelegibilidades, se cita a la Corte cuando indica que "los derechos políticos son esenciales en una sociedad democrática, pues propician 'el fortalecimiento de la democracia y el pluralismo político'" (Bastos \& Mioto Dos Santos, 2015: 173).

Pues bien, los requisitos que se establecen para las dignidades de elección popular que analizamos en nuestro trabajo, son: en el caso de la Presidenta o Presidente de la República debe ser ecuatoriano por nacimiento, 
haber cumplido treinta años de edad a la fecha de inscripción de su candidatura, estar en goce de los derechos políticos y no encontrarse incurso en ninguna de las inhabilidades o prohibiciones establecidas en la Constitución; y, para ser asambleísta se requerirá tener nacionalidad ecuatoriana, haber cumplido dieciocho años de edad al momento de la inscripción de la candidatura y estar en goce de los derechos políticos. A esos requisitos se agrega el procedimiento interno que deben realizar las organizaciones políticas reconocidas por el Consejo Nacional Electoral - de acuerdo a su Régimen Interno - y la obligatoriedad de realizar procesos de primarias para determinar quiénes serán candidatas y candidatos, procedimientos cruzados por aspectos políticos, sociales y hasta económicos que no son materia del presente artículo, pero que, sin duda, merece un análisis sociológico y hasta antropológico sobre la participación juvenil en elecciones.

Mediante la utilización de la técnica de la estadística, levantada gracias a los datos oficiales proporcionados por el Consejo Nacional Electoral, hemos podido percibir y determinar si la evolución constitucional en derechos electorales de las y los jóvenes ha significado un aumento de ese grupo poblacional en las pancartas de campaña y las papeletas de sufragio; lo que - colateralmente - nos indicará si la sola modificación normativa puede auto-arrogarse el desarrollo de los derechos. En consecuencia, este trabajo de investigación también es un esfuerzo por generar luces que le permitan al Estado afianzar las condiciones culturales, económicas, políticas y sociales para que las y los jóvenes ejerzan a plenitud su derecho a ser elegidos, tanto como primeros, segundos o terceros candidatos, principales o suplentes, aunque no siempre resulten electos, entendiéndose que el desarrollo de la norma o de un derecho tiene su punto de partida en la reforma o incorporación normativa; y su médula se encuentra en las garantías y mecanismos para ejercerlo.

\section{Jóvenes candidatos antes de la Constitución 2008}

En un estudio publicado acerca de la participación y abstención de las y los jóvenes en las elecciones al Parlamento Europeo de 2009 (Ugarte, Repáraz, \& Naval, 2013), se determinó que entre las personas con edades 
comprendidas entre los 18 y los 24 años, el $32 \%$ de los estudiantes acudió a votar porque considera muy importante el papel de la Unión Europea en la escena internacional. Por otro lado, en la publicación de los resultados parciales de una investigación realizada entre los años 2010 y 2011 cuya pretensión fue indagar la manera como van emergiendo las y los jóvenes de una universidad pública en cuanto sujetos políticos, preliminarmente se concluyó que la percepción general de participación política hace referencia al derecho de sufragar (el voto individual) y a las expresiones de protesta (principalmente marchas) que como jóvenes realizan, se anota que "la política se vive por parte de los jóvenes desde espacios formales y tradicionales, pasando por opciones de movilización y resistencia violentas, hasta las que privilegian el despliegue de argumentos para el logro de consensos y con ello el reconocimiento de su propia voz en cuanto se encuentran con la otredad desde la diferencia" (Díaz-Gómez \& Salamanca-Aragón, 2012, pág. 117). Por el contrario, el presente trabajo plantea un análisis donde las y los jóvenes son protagonistas en el escenario político-electoral, o al menos buscan serlo.

Así, el artículo 165 de la Constitución Política de la República que entró en vigencia el 11 de agosto de 1998, señalaba que "para ser Presidente de la República se requerirá ser ecuatoriano por nacimiento, estar en goce de los derechos políticos y tener por lo menos treinta y cinco años de edad, a la fecha de inscripción de su candidatura", por otra parte, se fijaba la edad de 25 años para ser candidato a diputado o candidata a diputada provincial (Artículo 127 idem). Sobre la base de dicha normativa constitucional, las organizaciones políticas, según los procedimientos legales e internos de la época, seleccionaron sus candidatos y candidatas para el binomio Presidencial y Congreso Nacional, reglas con las que se desarrollaron las elecciones generales convocadas para el año 2002, para reemplazar al ex Presidente Dr. Gustavo Noboa Bejarano, quien asumió el cargo por el derrocamiento del ex Presidente Dr. Jamil Mahuad Witt.

En ese escenario, el 1,30\% de los candidatos a diputados y las candidatas a diputadas provinciales, fueron jóvenes entre 18 a 25 años y la $21,18 \%$ tenían entre 26 a 35 años en el año de la elección, predominando la participación de las mujeres (Figuras 2 y 3), tal como se evidencia en el Figura 1. Sin embargo, existen diferencias cuando se revisa la información 
de este último elemento y encontramos que las y los jóvenes mayormente postularon en calidad de suplentes, reflejando una definición adultocéntrica en la conformación de las listas, reservadas especialmente, para quienes tenían entre 36 a 45 años, quienes constituían el 35,12\% del total de candidatas y candidatos a diputados.

\section{Figura 1.}

Elecciones 2002: Porcentajes de candidatas y candidatos a diputados por tipo de dignidad

-Principales $n$ Suplentes $\square$ Total candidaturas

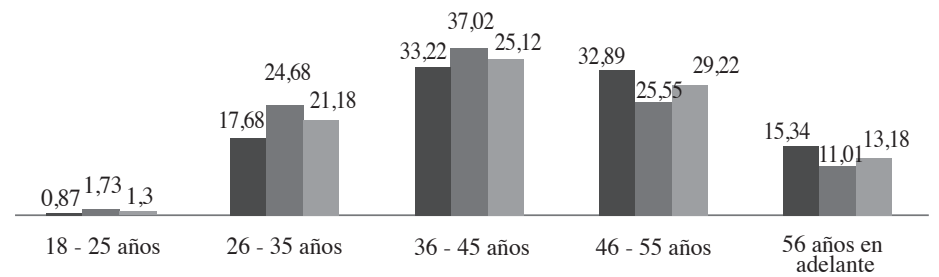

Fuente: Consejo Nacional Electoral.

Elaborado: por los autores.

\section{Figura 2.}

Elecciones 2002: Candidatas y candidatos diputados (principales) por grupos de edad y género

$$
\text { - Hombres } \quad \text { Mujeres } \quad \text { Total candidaturas principales }
$$

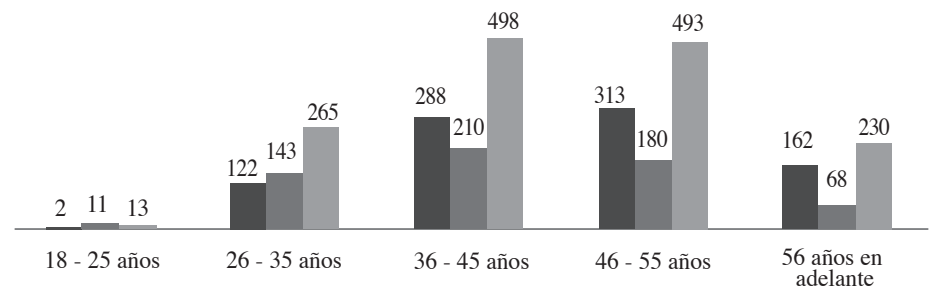

Fuente: Consejo Nacional Electoral.

Elaborado: por los autores. 


\section{Figura 3.}

Elecciones 2002: Candidatas y candidatos a diputados (suplentes) por grupos de edad y género

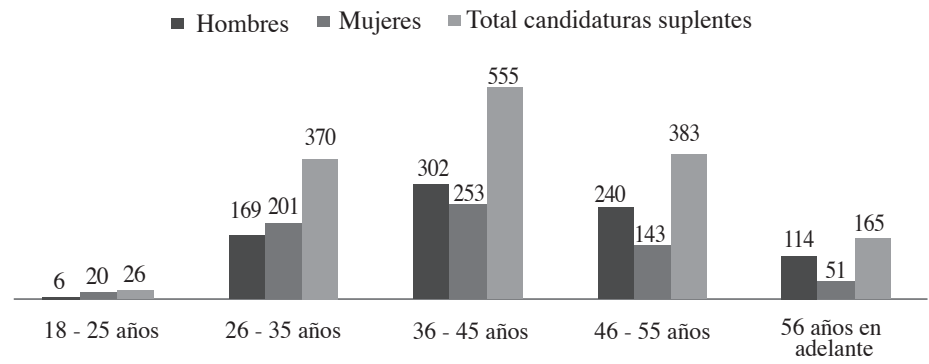

Fuente: Consejo Nacional Electoral.

Elaborado: por los autores.

En el caso de la elección del binomio presidencial, debemos reiterar que sólo podían postular quienes tenían - al momento de la inscripción - 35 años, por lo que, no existe información sobre el primer grupo de edad que estamos analizando, sin embargo, es importante observar cómo, cuándo y en qué escenario constitucional han participado como candidatas y candidatos personas con la edad mínima del requisito. En la Figura 2, se observa que el 9,09\% tenían entre 36 a 45 años, es decir dos que postularon para la Presidencia de la República del Ecuador, quienes además eran hombres (Figura 5); de los 11 binomios presidenciales, un total de 22 candidatos y candidatas, tan sólo 3 eran mujeres, de las cuales 1 era candidata presidencial (Figuras 5 y 6 ). 
CANDIDATOS JÓVENES EN LAS ELECCIONES GENERALES DE ECUADOR: EVOLUCIÓN EN EL ÚLTIMO QUINDENIO

\section{Figura 4.}

Elecciones 2002: Porcentajes de candidatas y candidatos del binomio presidencial por tipo de dignidad

$$
\text { •Presidencia } \quad \text { Vicepresidencia } \square \text { Total candidaturas }
$$

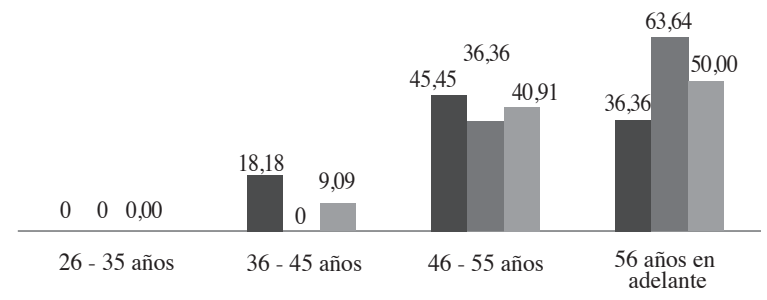

Fuente: Consejo Nacional Electoral.

Elaborado: por los autores.

\section{Figura 5.}

Elecciones 2002: Candidaturas para la Presidencia por grupos de edad y género

- Hombres a Mujeres $\quad$ Total candidaturas

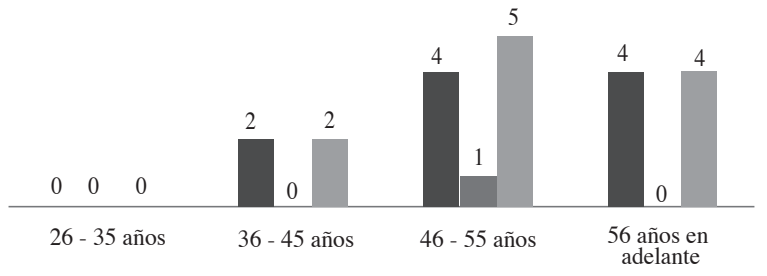

Fuente: Consejo Nacional Electoral.

Elaborado: por los autores. 


\section{Figura 6.}

Elecciones 2002: Candidaturas para la Vicepresidencia por grupos de edad y género

- Hombres Mujeres $\quad$ Total candidaturas

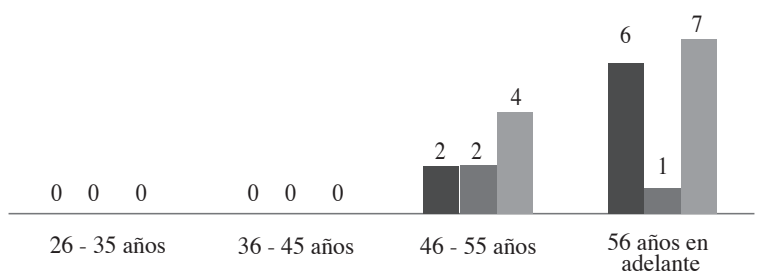

Fuente: Consejo Nacional Electoral.

Elaborado: por los autores.

Las normas constitucionales no habían cambiado, las aplicadas en el 2002 también lo fueron en el año 2006, por lo que las elecciones se planteaban en el mismo escenario jurídico, pese a que la coyuntura política había variado fuertemente y de alguna forma eso incidió en las modificaciones de los mecanismos de selección de candidatos y candidatas, aunque eso no haya significado un salto cuantitativo importante en la variable de edad. El $1,71 \%$ de candidatos y candidatas a diputaciones tenían entre 18 a 25 años, encontrándose en la dignidad de suplentes la mayor cantidad de dicho grupo; por otra parte, el $22,46 \%$ tenían entre 26 a 35 años y el 33,42\% 36 a 45 , manteniéndose, en los primeros tres grupos de edad, que las y los jóvenes ocuparon mayoritariamente las candidaturas a la dignidad de suplente, como se colige de la Figura 7. 


\section{Figura 7.}

Elecciones 2006: Porcentajes de candidatas y candidatos a diputados por tipo de dignidad

$$
\text { -Principales }=\text { Suplentes } \quad \text { Total candidaturas }
$$

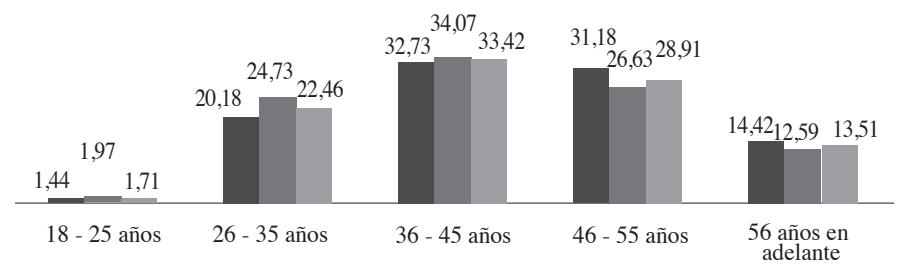

Fuente: Consejo Nacional Electoral.

Elaborado: por los autores.

Un patrón en las elecciones del año 2006 correspondiente a candidaturas a diputadas y diputados, es la concentración de mujeres en las candidaturas jóvenes y de los hombres en las candidaturas de los grupos de edad mayores a 46 años; por ejemplo, de 366 candidaturas de quienes tenían entre 26 a 35 años, 159 correspondieron a mujeres, contrario a lo que se reflejó en el grupo de edad de 46 a 55 años, en el que 247 fueron hombres de un total de 411 postulaciones, tendencia que se profundiza en el último grupo de edad, como lo demuestran las Figuras 8 y 9. Con estos datos se pueden emerger muchos análisis de género y políticos respecto a la dinámica y a la cultura política de las organizaciones y de las percepciones que se tienen del electorado, sin embargo, eso amerita otra investigación en la que pudiera incorporarse el punto de llegada, es decir, los indicadores de género y edad de quienes resultaron electos, donde se pueden obtener otros resultados interesantes, ya que, en todo caso, "las prácticas políticas de los jóvenes se tornan en un campo inagotable de saber y de producción investigativa -casi-permanente, pues son éstos quienes con sus apuestas, luchas y creaciones logran desafiar el poder dominante y la alienación del capitalismo actual en la subjetividad" (Bermúdez, 2013, pág. 273). 


\section{Figura 8.}

Elecciones 2006: Candidatas y candidatos a diputados (principales) por grupos de edad y género

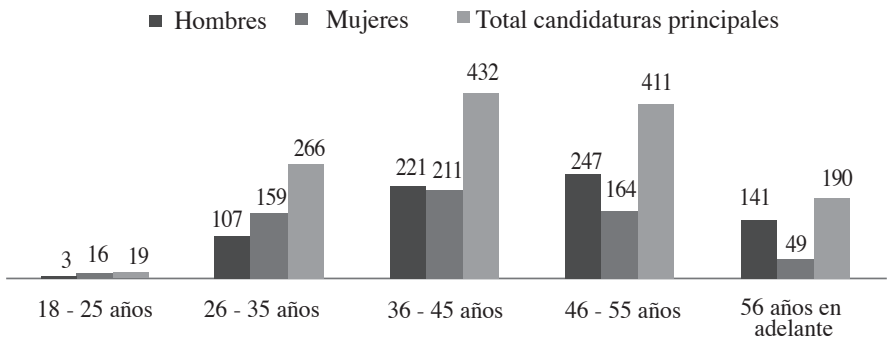

Fuente: Consejo Nacional Electoral.

Elaborado: por los autores.

Figura 9.

Elecciones 2006: Candidatas y candidatos a diputados (suplentes) por grupos de edad y género

- Hombres - Mujeres - Total candidaturas suplentes

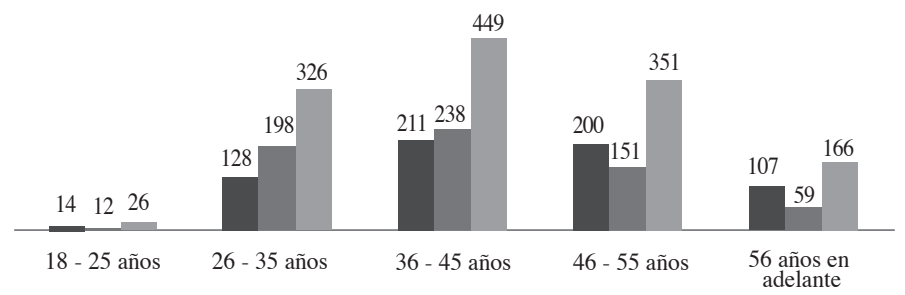

Fuente: Consejo Nacional Electoral.

Elaborado: por los autores.

En lo referente a la elección del Binomio Presidencial en el año 2006, existen variantes importantes, quizá propias de las condiciones políticas de la época -ya que, como subrayamos, no existieron modificaciones en la norma constitucional-, considerando que aumentaron los porcentajes de participación en los dos primeros grupos de edad y disminuyeron en los dos últimos (Figura 
10); lo que tuvo variaciones fue la cantidad de mujeres que participaron, igualmente respecto del tipo de dignidad, predominando su postulación a la Vicepresidencia de la República y prevaleciendo la participación de los hombres en todos los grupos de edad, tal como se evidencia en las Figuras 11 y 12 .

\section{Figura 10.}

Elecciones 2006: Porcentajes de candidatas y candidatos del binomio presidencial por tipo de dignidad

-Presidencia $\square$ Vicepresidencia $\square$ Total candidaturas

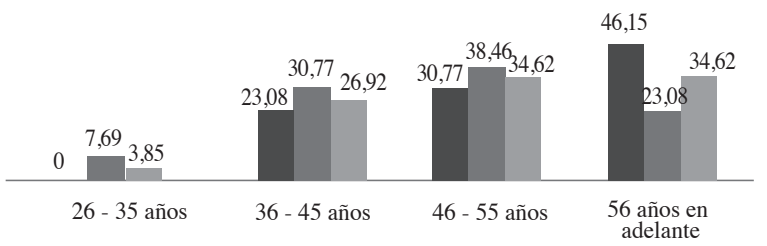

Fuente: Consejo Nacional Electoral.

Elaborado: por los autores.

\section{Figura 11.}

Elecciones 2006: Candidaturas para la Presidencia por grupos de edad y género

- Hombres Mujeres $\quad$ Total candidaturas

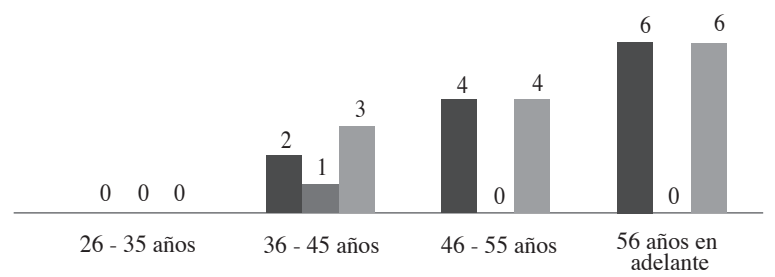

Fuente: Consejo Nacional Electoral.

Elaborado: por los autores. 


\section{Figura 12.}

Elecciones 2006: Candidaturas para la Vicepresidencia por grupos de edad y género

- Hombres $\quad$ Mujeres $\quad$ Total candidaturas

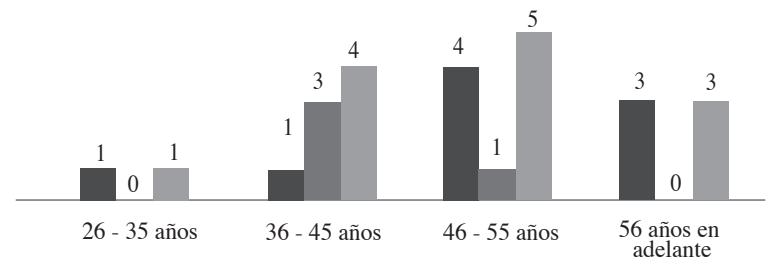

Fuente: Consejo Nacional Electoral.

Elaborado: por los autores.

\section{Jóvenes candidatos desde la Constitución 2008}

Mediante Decreto Ejecutivo No. 02 de fecha 15 de enero del 2007, suscrito por el Eco. Rafael Correa Delgado, en su calidad de Presidente Constitucional del Ecuador, se convocó a Consulta Popular para decidir si se debía o no convocar a una Asamblea Nacional Constituyente para la redacción de una nueva Constitución; aprobada la iniciativa por el pueblo ecuatoriano, se instaló la Asamblea en Montecristi, provincia de Manabí, para dar nacimiento a un nuevo cuerpo constitucional, escenario en el que participó gran parte de los movimientos sociales, especialmente jóvenes y mujeres, en procesos de incidencia que permitieron profundizar el reconocimiento de los derechos humanos; los autores fueron parte del Acuerdo Nacional por la Constituyente Juvenil, plataforma de organizaciones juveniles que postularon el Mandato Juvenil y exigieron el reconocimiento de las y los jóvenes como sujetos de derechos, seguramente dicha coyuntura y la voluntad política del proceso denominado "Revolución Ciudadana", permitieron que, con la aprobación del nuevo texto constitucional mediante referéndum, el 20 de octubre del 2008 entre en vigencia la Constitución que redujo el requisito de edad para candidatos y candidatas a asambleístas (antes diputados) y binomio presidencial. 
Con una nueva Constitución, el Ecuador enfrentó un escenario electoral completamente distinto en términos de condiciones jurídicas y políticas del sistema electoral, desde cambio de denominaciones de dignidades hasta la modificación de requisitos como se señaló anteriormente; es así, que el artículo 119 establece que para ser candidato o candidata a asambleísta se requiere "haber cumplido dieciocho años de edad al momento de la inscripción de la candidatura", es decir, 7 años menos que la edad requerida hasta el 19 de octubre de 2008; y, para ser candidato o candidata a una de las dignidades del binomio presidencial, según el artículo 142, se deberá "haber cumplido treinta años de edad a la fecha de inscripción de su candidatura", esto significa, 5 años menos que lo establecido en la Constitución aprobada en el año 1998; empero surgen algunas inquietudes: ¿Cuánto incide socialmente el cambio de la norma constitucional? ¿Los patrones culturales se modifican con las reformas de las normas jurídicas? ¿Los y las jóvenes tenían oportunidad de ejercer las nuevas oportunidades electorales en un escenario político - aparentemente - adultocéntrico? No todo cambio normativo tiene aplicación inmediata, precisa que sea acompañado de un proceso social y político dialéctico, no sujeto al análisis de la presente investigación, pero que sin lugar a dudas para las y los jóvenes conjugaron dichos elementos en las Elecciones 2009. Además que existe una realidad innegable, el hecho de que "los partidos políticos tienen el monopolio de proponer candidatos para los diferentes cargos de elección popular. Si los jóvenes no tienen participación electoral, en gran medida es por falta de inclusión en las estructuras partidistas" (Silvestre Pineda, 2013, pág. 9).

Los jóvenes que tenían entre 18 a 25 años representaron el 14,16\% de los candidatos y candidatas a asambleístas y el $23,15 \%$ quienes tenían entre 26 a 35 años, en el primer caso con un aumento de 12 puntos porcentuales, sin que ello implique una significativa reducción para el segundo grupo, por el contrario, las reducciones se dan en los dos últimos grupos de edad estudiados; sin embargo, se mantienen los patrones de que los jóvenes mayormente ocupan las dignidades de suplentes y el de género respecto a que las mujeres jóvenes y hombres adultos tienen preferencia en las candidaturas, de acuerdo a lo observado en las Figuras 13, 14 y 15; en todo caso, y sin lugar a dudas, pasar de 19 candidaturas principales de jóvenes entre 18 a 25 
años, a inscribir 175, es un cambio cuantitativo significativo y, seguramente, histórico en la democracia ecuatoriana.

\section{Figura 13.}

Elecciones 2009: Porcentajes de candidatas y candidatos a asambleístas por tipo de dignidad

$$
\text { - Principales } \square \text { Suplentes } \square \text { Total candidaturas }
$$

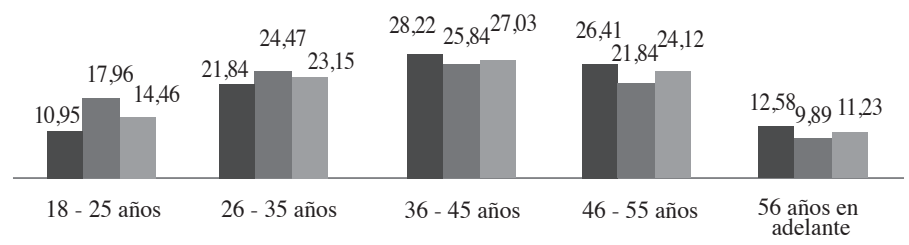

Fuente: Consejo Nacional Electoral.

Elaborado: por los autores.

\section{Figura 14.}

Elecciones 2009: Candidatas y candidatos a asambleistas (principales) por grupos de edad y género

- Hombres Mujeres $\quad$ Total candidaturas principales

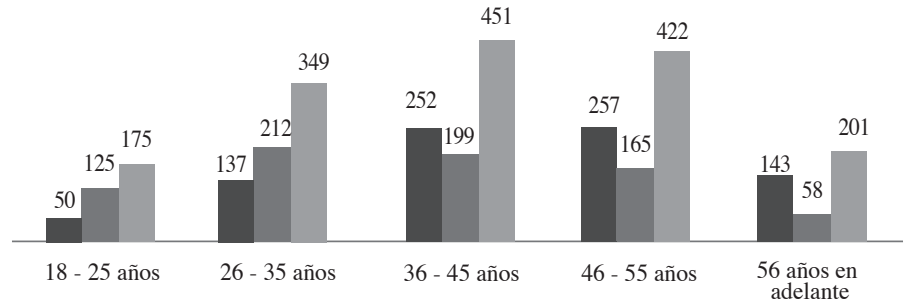

Fuente: Consejo Nacional Electoral.

Elaborado: por los autores. 


\section{Figura 15.}

Elecciones 2009: Candidatas y candidatos a asambleistas (suplentes) por grupos de edad y género

- Hombres - Mujeres - Total candidaturas suplentes

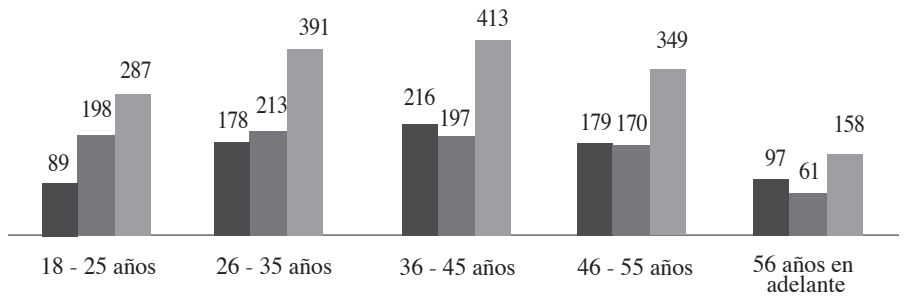

Fuente: Consejo Nacional Electoral.

Elaborado: por los autores.

En el caso de la elección del binomio presidencial, la nueva norma constitucional no significó el aumento de candidatos y candidatas en el grupo de edad de 26 a 35 años, por el contrario, el porcentaje fue de $0 \%$ y hubo un aumento en el grupo de edad de 46 a 55 años, seguramente respondiendo a la coyuntura política del momento, como se observa en la Figura 16; por lo que, no se refleja que la modificación constitucional haya incidido inmediatamente en estas dignidades, quizá porque la novedad respecto a la edad, se dio en las elecciones 2006 y el país se enfrentaba a una reelección presidencial después de muchas décadas; es decir, no conjugaron los elementos que habíamos señalado como históricos para que las organizaciones políticas se propusieran inscribir a personas que tenían entre 30 a 34 años de edad. Otro aspecto recurrente, pese al cambio constitucional, es la preferencia para los hombres en la definición de las candidaturas al interior del sistema de organizaciones políticas (Figuras 17 y 18). 


\section{Figura 16.}

Elecciones 2009: Porcentajes de candidatas y candidatos del binomio presidencial por tipo de dignidad

- Presidencia -Vicepresidencia $\quad$ Total candidaturas

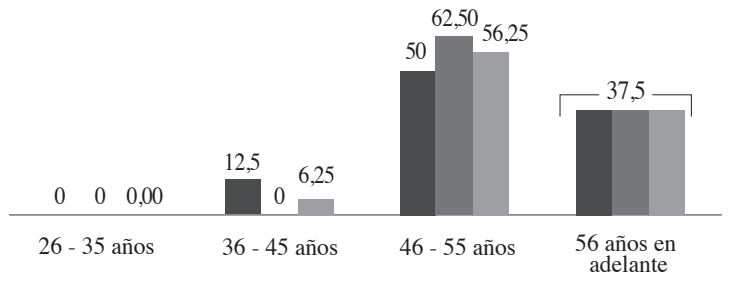

Fuente: Consejo Nacional Electoral.

Elaborado: por los autores.

Figura 17.

Elecciones 2009: Candidaturas para la Presidencia por grupos de edad y género

- Hombres $\quad$ Mujeres Total candidaturas

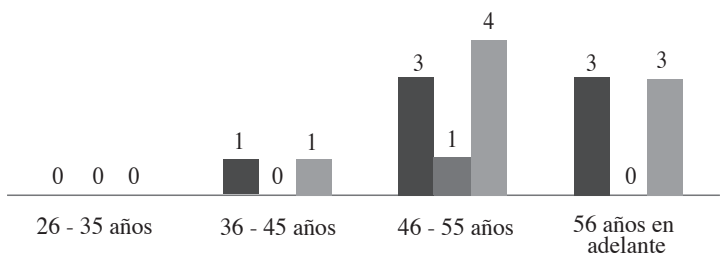

Fuente: Consejo Nacional Electoral.

Elaborado: por los autores. 


\section{Figura 18.}

Elecciones 2009: Candidaturas para la Vicepresidencia por grupos de edad y género

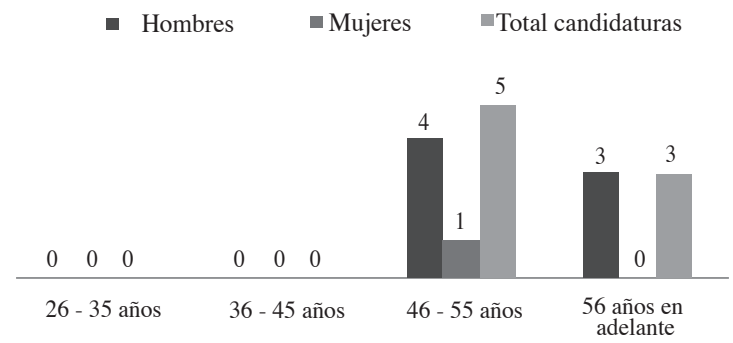

Fuente: Consejo Nacional Electoral.

Elaborado: por los autores.

Las Elecciones Generales de 2013 constituyeron un leve retroceso en el ejercicio del derecho a ser elegido de los y las jóvenes, considerando que las candidaturas de quienes tenían entre 18 a 25 años se redujeron en más de 3 puntos porcentuales, en lo que constituía la segunda experiencia electoral con la nueva Constitución, en la que se ratificaba la mayoritaria participación juvenil en la dignidad de suplentes y la preferencia política de postular mujeres jóvenes como candidatas, lo que podría reflejar que las mujeres van perdiendo oportunidades electorales en la medida que avanzan en su edad y que en esa misma línea los hombres, por el contrario, las van ganando, quizá propio de una cultura política machista, situación que, insistimos, amerita su propio estudio (Figuras 19, 20 y 21). 


\section{Figura 19.}

Elecciones 2013: Porcentajes de candidatas y candidatos a asambleístas por tipo de dignidad

- Principales $\quad$ Suplentes $\quad$ Total candidaturas

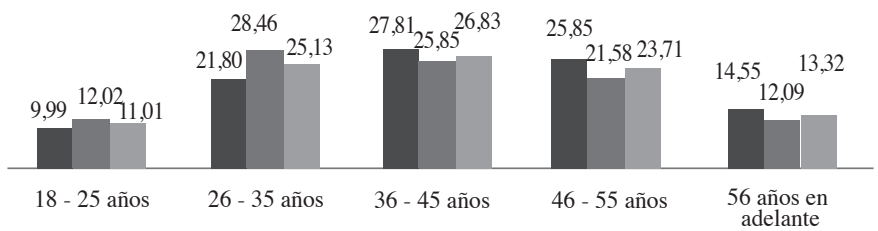

Fuente: Consejo Nacional Electoral.

Elaborado: por los autores.

\section{Figura 20.}

Elecciones 2013: Candidatas y candidatos a asambleístas (principales) por grupos de edad y género

- Hombres $\quad$ Mujeres $\quad$ Total candidaturas

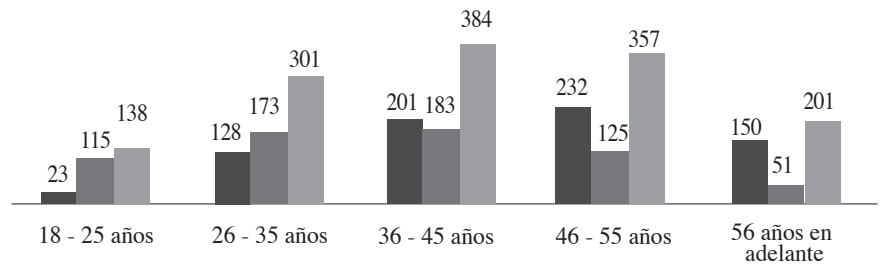

Fuente: Consejo Nacional Electoral.

Elaborado: por los autores. 


\section{Figura 21.}

Elecciones 2013: Candidatas y candidatos a asambleistas (suplentes) por grupos de edad y género

- Hombres $\quad$ Mujeres $\quad$ Total candidaturas suplentes

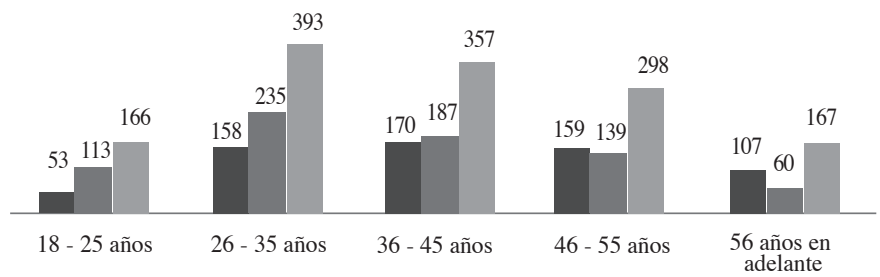

Fuente: Consejo Nacional Electoral.

Elaborado: por los autores.

En la elección del binomio presidencial, el 2013 fue favorable para quienes tenían entre 36 a 45 años de edad, por cuanto ocuparon el $50 \%$ de las candidaturas, de un total de 16, especialmente en la dignidad de Vicepresidente o Vicepresidenta, como se colige de la Figura 22. En cuanto a la participación de las mujeres, ninguna organización política las postuló para la dignidad de Presidenta, las ocho candidaturas fueron ocupadas por hombres; empero, en la dignidad de Vicepresidente o Vicepresidenta, en 5 de las 8 candidaturas fueron inscritas mujeres, de las cuales 3 tenían entre 36 y 45 años (Figuras 23 y 24). 


\section{Figura 22.}

Elecciones 2013: Porcentajes de candidatas y candidatos del binomio presidencial por tipo de dignidad

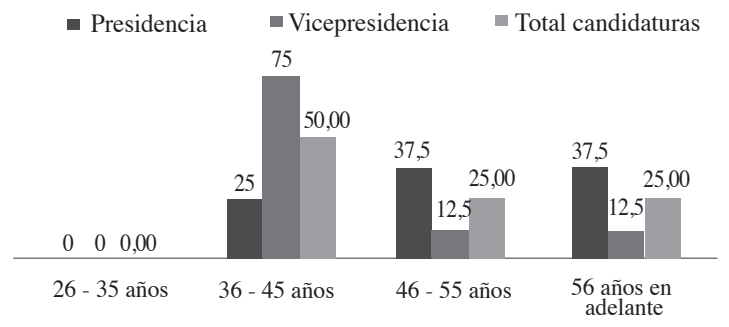

Fuente: Consejo Nacional Electoral.

Elaborado: por los autores.

Figura 23.

Elecciones 2013: Candidaturas para la Presidencia por grupos de edad y género

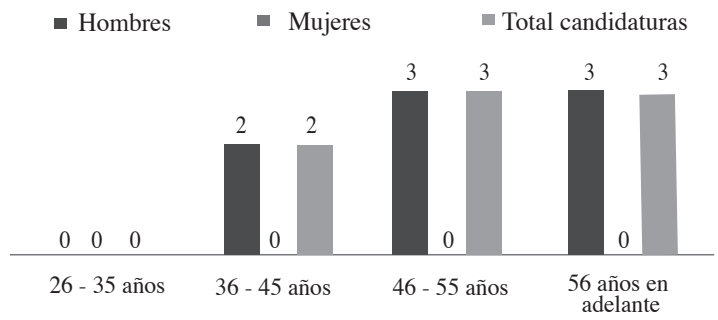

Fuente: Consejo Nacional Electoral.

Elaborado: por los autores. 


\section{Figura 24.}

Elecciones 2013: Candidaturas para la Vicepresidencia por grupos de edad y género

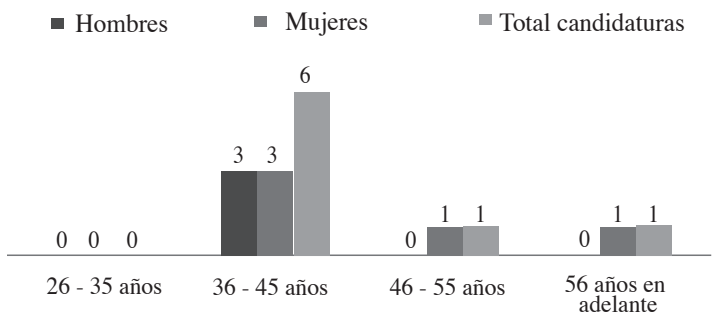

Fuente: Consejo Nacional Electoral.

Elaborado: por los autores.

¿Las condiciones políticas fueron favorables para las y los jóvenes en todas las elecciones después del 2008? Como observamos en las Elecciones Generales 2013, correspondiente a las dignidades de asambleístas principales y suplentes, el impacto positivo de la nueva Constitución en el 2009 no se sostuvo en el tiempo y significó un leve retroceso porcentual, lo que se profundiza en la elección 2017, por lo que se observa, hasta las recientes elecciones, que existe una tendencia en elevar la postulación de candidatas y candidatos a asambleístas que tengan 46 años en adelante. Los dos primeros grupos de edad que atiende la presente investigación, disminuyeron en la elección de Asambleístas, quienes tenían entre 18 a 25 años alcanzan el $10,05 \%$ y el grupo de entre 26 a 35 llega al $22,86 \%$, mientras que el grupo que más asciende es el de 56 años en adelante, que aumentó más de 3 puntos porcentuales, como se observa en la Figura 24; en la cual se ratifica la mayor participación de las y los jóvenes en la dignidad de suplentes. Además, se confirma el patrón recurrente en el último quindenio respecto al predominio de las mujeres en las candidaturas jóvenes y los hombres en las adultas, tanto en las dignidades principales como en las suplencias, así lo muestran las Figuras 25 y 26. 


\section{Figura 25.}

Elecciones 2017: Porcentajes de candidatas y candidatos a asambleístas por tipo de dignidad

$$
\text { -Principales } \quad \text { Suplentes Total candidaturas }
$$

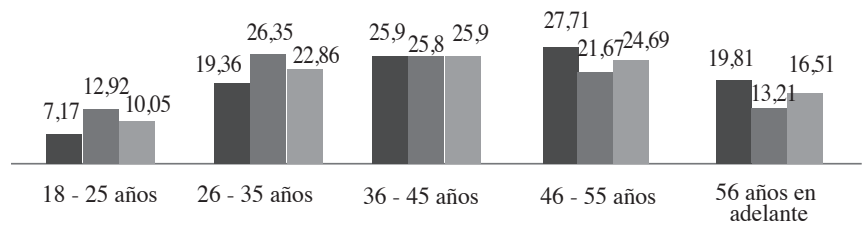

Fuente: Consejo Nacional Electoral.

Elaborado: por los autores.

Figura 26.

Elecciones 2017: Candidatas y candidatos a asambleistas (principales) por grupos de edad y género

$$
\text { - Hombres } \quad \text { Mujeres Total candidaturas principales }
$$

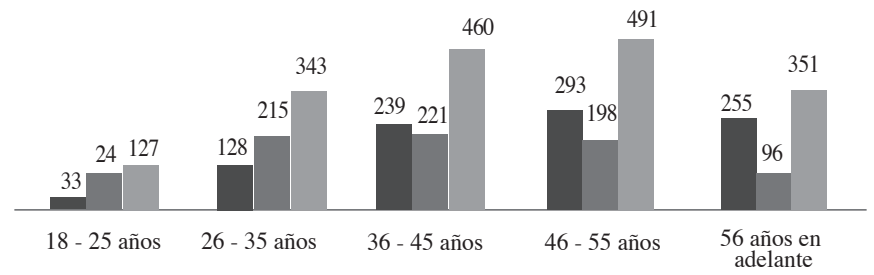

Fuente: Consejo Nacional Electoral.

Elaborado: por los autores. 


\section{Figura 27.}

Elecciones 2017: Candidatas y candidatos a diputados (suplentes) por grupos de edad y género

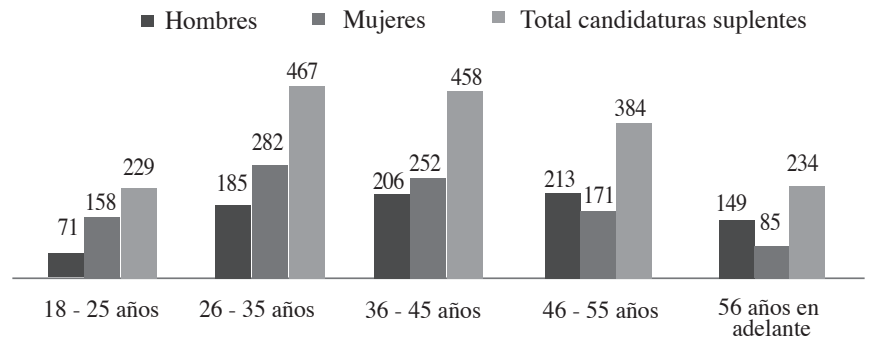

Fuente: Consejo Nacional Electoral.

Elaborado: por los autores.

La particularidad de la elección del binomio presidencial en las Elecciones Generales de 2017, radica en que, a diferencia de los otros procesos del último quindenio, constituye el único proceso con participación de personas que tenían entre 26 a 35 años en la dignidad de Presidente o Presidenta de la República, además de ser la primera ocasión en la que participa un candidato con 34 años de edad y otro con 35; en el quindenio sólo se registraba un candidato con 35 años, que postuló a la dignidad de Vicepresidente en las Elecciones Generales de 2006, por lo que, se evidencia que cambiaron las condiciones políticas y que, en la elección del binomio presidencial, la nueva Constitución tiene un efecto material en el 2017. Sin embargo, no se registran candidatos y candidatas de entre 36 a 45 años, así mismo, observamos un significativo aumento en el grupo de 56 años en adelante, de acuerdo a la Figura 27. En el aspecto de género se reduce a 3 la participación de las mujeres en las candidaturas del binomio presidencial, de las cuales solo una consta como inscrita para la dignidad de Presidenta de la República (Figuras 28 у 29$)$. 


\section{Figura 28.}

Elecciones 2017: Porcentajes de candidatas y candidatos del binomio presidencial por tipo de dignidad

$$
\text { - Presidencia Vicepresidencia Total candidaturas }
$$

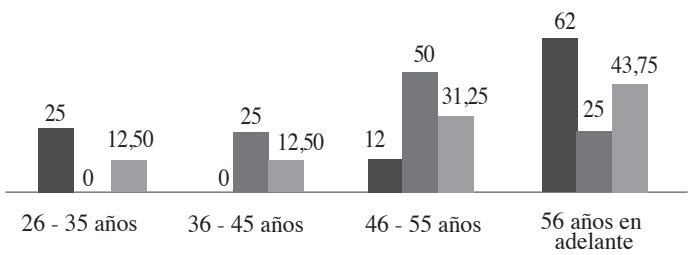

Fuente: Consejo Nacional Electoral.

Elaborado: por los autores.

Figura 29.

Elecciones 2017: Candidaturas para la Presidencia por grupos de edad y género

$$
\text { - Hombres } \quad \text { Mujeres Total candidaturas }
$$

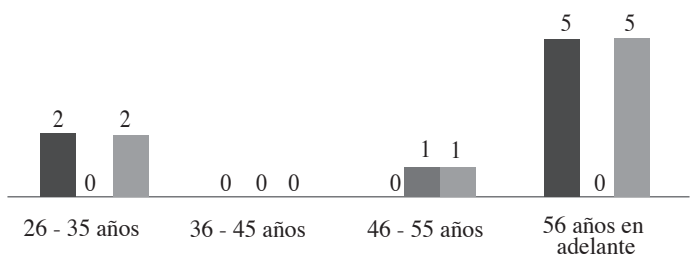

Fuente: Consejo Nacional Electoral.

Elaborado: por los autores. 


\section{Figura 30.}

Elecciones 2017: Candidaturas para la Vicepresidencia por grupos de edad y género

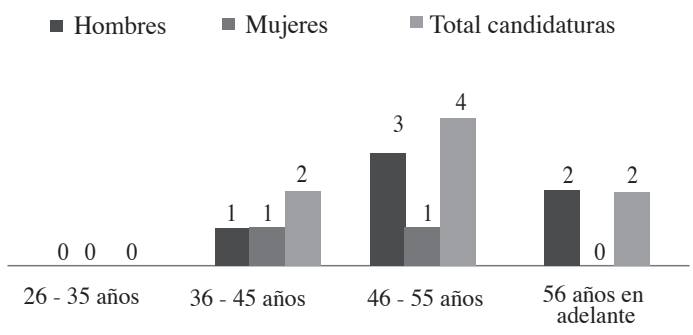

Fuente: Consejo Nacional Electoral.

Elaborado: por los autores.

\section{Evolución de las candidaturas de jóvenes en el último quindenio}

En una mirada lineal de la participación de las y los jóvenes observamos una tendencia al decrecimiento en los dos últimos procesos electorales, pese al considerable aumento que significó la entrada en vigencia de la Constitución 2008, por consecuencia, un crecimiento de la participación de quienes tienen 56 años en adelante, especialmente en las candidaturas principales, tal como se colige de las Figuras 30, 31 y 32. La caída porcentual en relación al 2009 con el 2017 es de 4,41 puntos en las candidaturas legislativas principales y suplentes -, lo que refleja modificaciones en las condiciones políticas, pero sobre todo, en términos jurídicos, una menor incorporación de la población joven en el ejercicio del derecho a ser elegido, pero no por falta de normativa constitucional que lo reconozca, sino más bien por falta de normas infraconstitucionales y condiciones materiales que lo garanticen. $\mathrm{Al}$ respecto se puede anotar que "a diferencia del género, la ley electoral no establece ninguna consideración que obligue a los partidos políticos a la equidad de edad para establecer las candidaturas. Es decir, son los partidos políticos los que determinan si toman o no un criterio etario para postular a sus candidatos" (Aguilar-López, 2013, pág. 86), aunque igual concurren otras diferentes circunstancias. 


\section{Figura 31.}

Evolución porcentual de candidaturas legislativas por grupos de edad

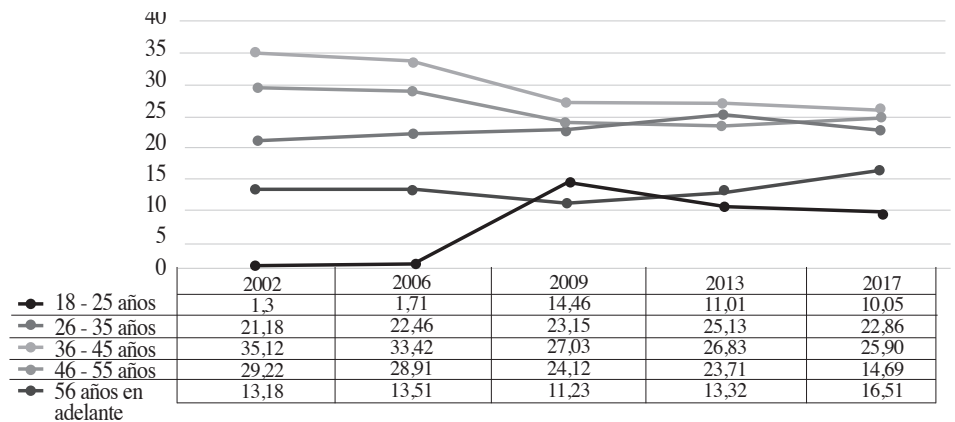

Fuente: Consejo Nacional Electoral.

Elaborado: por los autores.

\section{Figura 32.}

Evolución porcentual de candidaturas legislativas principales por grupos de edad

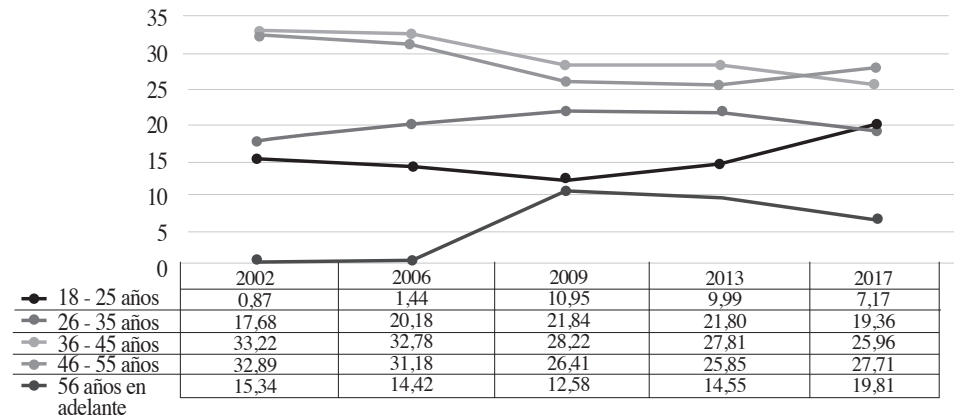

Fuente: Consejo Nacional Electoral.

Elaborado: por los autores. 


\section{Figura 33.}

Evolución porcentual de candidaturas legislativas suplentes por grupos de edad

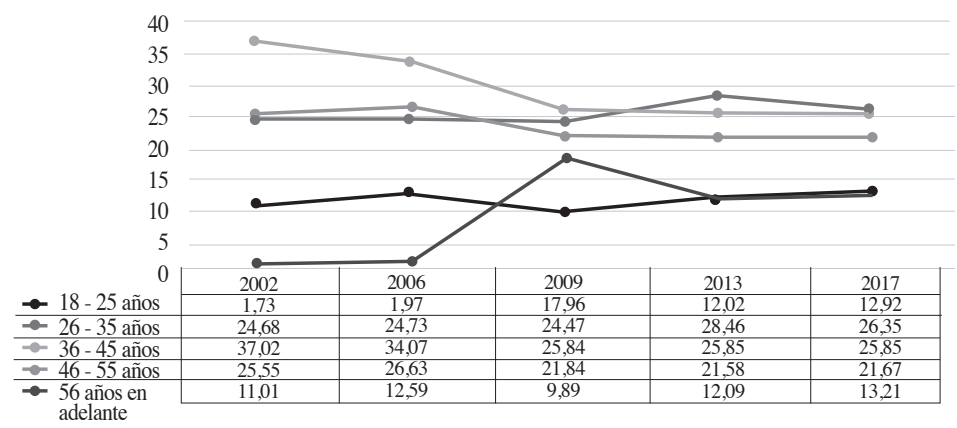

Fuente: Consejo Nacional Electoral.

Elaborado: por los autores.

La evolución lineal en la elección del binomio presidencial del último quindenio, es algo menos desalentadora para las y los jóvenes, puesto que en las últimas elecciones hubo un salto de 12,50 puntos respecto del 2013 en el grupo de edad de 26 a 35 años, que corresponde a la dignidad de Presidente o Presidenta de la República; así mismo, el grupo de 36 a 45 años se ha mantenido por encima del $25 \%$ de participación y se refleja un importante crecimiento de quienes tenían 56 años o más en las elecciones 2017. En la dignidad de Vicepresidencia, sólo se registra la participación de jóvenes en el proceso electoral del año 2006, como se refleja en las Figuras 33, 34 y 35; en todos los casos, las condiciones políticas son desfavorables para las mujeres, especialmente para las jóvenes, como se ha podido reflejar en el presente análisis.

Debemos precisar que ninguna estadística podría asegurar ni garantizar la presencia de las y los jóvenes en los futuros procesos electorales, por el contrario, "la inclusión política de las personas jóvenes debe ser concebida como un proceso continuo y constante, no como una acción puntual en el tiempo que sólo beneficie a los jóvenes del presente" (Álvarez-Torres \& MonsiváisCarrillo, 2016, pág. 170); pues, en vista “de que los jóvenes sean el componente más numeroso de la población, condiciona al Estado y a la sociedad a destinar recursos para ser invertidos en ellos, en la perspectiva de obtener una alta 
rentabilidad. Esto obliga a pensar en planes ambiciosos, incluyentes, serios, consistentes, de continuidad y larga permanencia, que trasciendan los períodos sexenales" (Cordera-Campos \& Victoria-Toscano, 2010, pág. 92).

\section{Figura 34.}

Evolución porcentual de candidaturas del binomio presidencial por grupos de edad

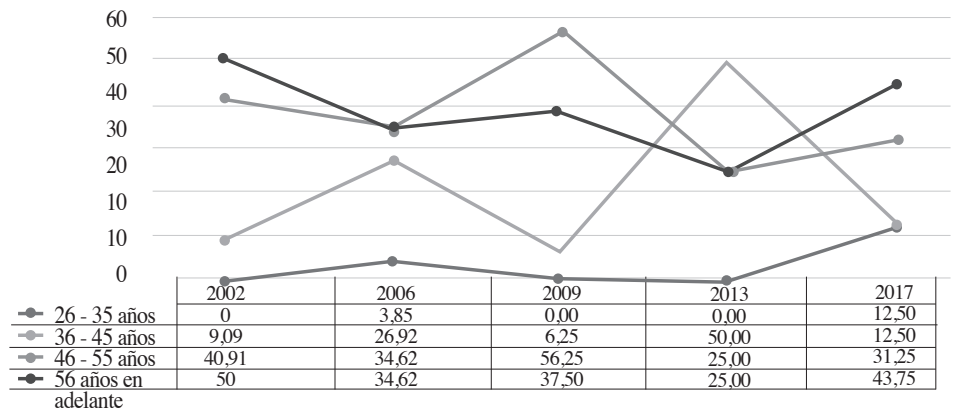

Fuente: Consejo Nacional Electoral.

Elaborado: por los autores.

\section{Figura 35.}

Evolución porcentual de candidaturas a la Presidencia por grupos de edad

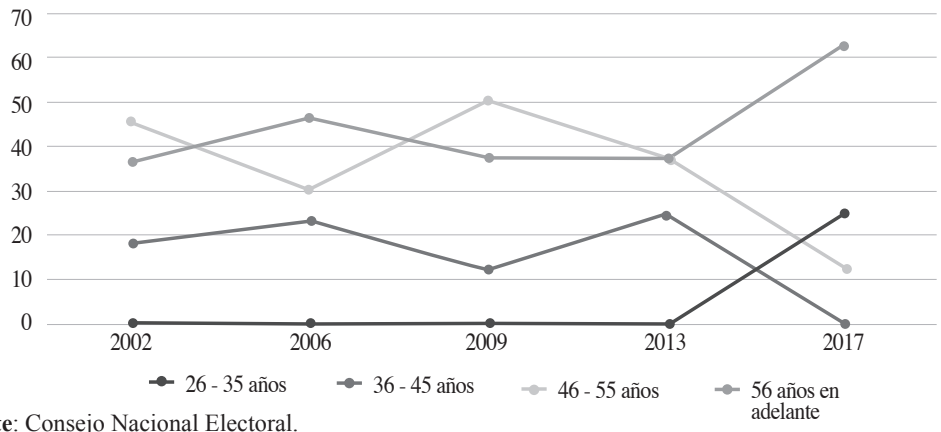

Fuente: Consejo Nacional Electoral.

Elaborado: por los autores. 


\section{Figura 36.}

Evolución porcentual de candidaturas a la Vicepresidencia por grupos de edad

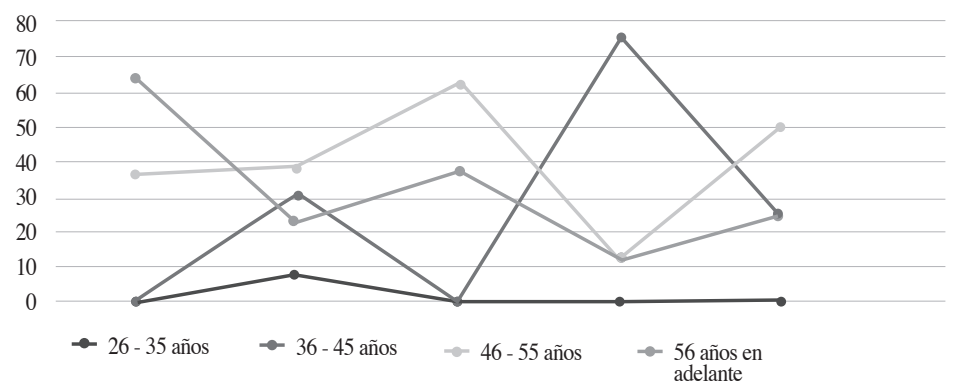

Fuente: Consejo Nacional Electoral.

Elaborado: por los autores.

\section{Conclusiones}

Los hallazgos de la presente investigación, permiten concluir que se mantienen los patrones de que las y los jóvenes mayormente ocupan las dignidades de candidatos suplentes, pese a que se incrementó su participación electoral en las candidaturas, lo que coincide con otros estudios similares que concluyen indicando que "los jóvenes de entre 21 y 29 años son utilizados por los partidos políticos para ocupar los lugares en la lista con menos posibilidades de ser electos, o como se dice coloquialmente: son utilizados para rellenar espacios" (Aguilar-López, 2013, pág. 94). Además, se pudo identificar que en las listas pluripersonales, aun siendo candidatos, fueron muy pocos los y las jóvenes que resultaron electos para la representación en la Asamblea Nacional, posiblemente por su ubicación en la conformación de las listas que, como es de conocimiento público, en escasas ocasiones las y los jóvenes fueron protagonistas como candidatos principales en los tres primeros escaños.

Por otro lado, se observó una marcada tendencia respecto de la preferencia de postular mujeres jóvenes como candidatas, de igual manera suplentes en la mayoría de los casos, pero conforme más años de edad, esas 
oportunidades se fueron reduciendo. Es decir, las mujeres van perdiendo oportunidades electorales en la medida que avanzan en su edad y en esa misma línea los hombres, por el contrario, las van ganando y en espacios protagónicos, quizá propio de una cultura política machista, situación que, insistimos, amerita su propio estudio. Sin embargo, la superioridad de las mujeres en este aspecto, encuentra una clara respuesta en las políticas de cuotas que se establecieron a favor de dicho género, además, de las acertadas acciones que se desplegaron en todo el Estado para generar condiciones jurídicas, políticas y culturales que coadyuven a asegurar paridad, alternancia y secuencialidad; desde el Consejo Nacional Electoral se diseñaron y ejecutaron mecanismos de supervisión, asesoría y capacitación a las organizaciones políticas, así como, el efectivo control legal a las listas que solicitaron inscribirse.

Además, se considera que los cambios jurídicos no implican, per se, los cambios materiales para el ejercicio de los derechos, al menos en estos casos. Más allá de las decisiones normativas, se necesitan de condiciones sociales, económicas e infraconstitucionales que hagan efectivo el goce de los derechos electorales; y, que aun llegando al punto de concurrencia de esas condiciones jurídicas y materiales, no significa que se sostengan en el tiempo, es decir, el ejercicio del derecho a ser elegido es esencialmente dinámico, más aún con una población igual de dinámica como las juventudes, en donde aparece un tercer elemento que son las condiciones políticas que terminan siendo, inclusive, mucho más variables y determinantes que las condiciones económicas.

Entonces surge la necesidad de, pese a lo señalado y con creatividad, incorporar normas y políticas públicas que garanticen plenamente el derecho a ser elegido de las y los jóvenes, debiendo estudiarse si las cuotas serían efectivas o la promoción de sus capacidades y liderazgo político, siendo indispensable un proceso que permita incluirles en la política y lo político, puesto que, puede resultar, que nos encontramos en un complejo escenario de desinterés propio de la evolución cultural de lo juvenil; en todo caso, evaluar y ampliar el programa "Yo Decido" del Consejo Nacional Electoral y fortalecer el Consejo Nacional para la Igualdad Intergeneracional, son objetivos a corto plazo para encontrar un resultado más favorable a las y los jóvenes en las Elecciones Seccionales del 2019. 
Finalmente se concluye que el impacto de la modificación constitucional respecto al derecho a ser elegido, significó un salto cuantitativo y cualitativo en la democracia representativa del Ecuador, sobre todo por la transformación que generó al incorporar a más jóvenes en el escenario electoral y obligar al sistema político a pensar nuevas formas de inclusión política y de selección de candidaturas, aunque les haya tocado debatirse en una cultura política que, en gran parte, no vio la oportunidad de contar con sus capacidades para mejorar las prácticas en el ejercicio del poder público, deficiencia aumentada en las últimas elecciones en las que creció el número de personas mayores de 45 años en las listas, hecho que nos cuestiona si constituye un retroceso para las y los jóvenes y la cultura democrática del país. 


\section{Referencias}

Aguilar-López, J. (julio - diciembre de 2013). "La participación de los jóvenes como candidatos al Poder Legislativo en el proceso electoral de 2012". Polis: Investigación y Análisis Sociopolítico y Psicosocial, 9(2), 79 - 111. Obtenido de http://www.redalyc.org/articulo.oa?id=72630717004

Álvarez-Torres, C., \& Monsiváis-Carrillo, A. (septiembre - diciembre de 2016). "Democracia, capacidades deliberativas e inclusión política juvenil: el caso de Baja California". Revista Mexicana de Ciencias Políticas y Sociales, 60(225), 161 - 202. Obtenido de http://www.scielo.org.mx/ scielo.php?script=sci_arttext\&pid=S0185-19182015000300161\&lang=es

Bastos, L., \& Mioto Dos Santos, R. (2015). "Los estándares interpretativos de la Corte Interamericana de Derechos Humanos en materia de derechos políticos y la inconvencionalidad de la ley brasileña de inelegibilidades". Estudios Constitucionales, 13(1), 163 - 202. Obtenido de http://www.scielo.cl/ scielo.php?script=sci_arttext\&pid=S0718-52002015000100006\&lang=es

Bermúdez, M. M. (abril de 2013). "Trazos e itinerarios políticos de jóvenes: Comentarios a libro". Nómadas (38), 271 - 273. Obtenido de http://www. redalyc.org/articulo.oa?id $=105127475019$

Bivort, B., Martínez-Labrín, S., Orellana, C., \& Farías, F. (septiembre de 2016). "Mujeres jóvenes y ciudadanía en Chile: Una mirada a las nuevas configuraciones". Revista de Sociología e Política, 24(59), 25 -37. Obtenido de http://www.scielo.br/scielo.php?script=sci_abstract\&pid=S0104$44782016000300025 \& \operatorname{lng}=$ en\&nrm=iso\&tlng=es

Contreras-Aguirre, G., \& Morales-Quiroga, M. (julio - diciembre de 2014). “Jóvenes y participación electoral en Chile 1989-2013. Analizando el efecto del voto voluntario". Revista Latinoamericana de Ciencias Sociales, 
Niñez y Juventud, 12(2), 597 - 615. Obtenido de http://www.redalyc.org/ articulo.oa? $\mathrm{id}=77331488006$

Cordera-Campos, R., \& Victoria-Toscano, J. L. (agosto de 2010). "Políticas para los jóvenes". Economíaunam, 7(20), 86 - 93. Obtenido de http://www. redalyc.org/articulo.oa?id=363533404006

Díaz-Gómez, Á., \& Salamanca-Aragón, L. A. (abril - junio de 2012). "Los jóvenes son sujetos políticos... a su manera". Utopía y Praxis Latinoamericana, 17(57), 109 - 117. Obtenido de http://www.redalyc.org/ articulo.oa? $\mathrm{id}=27922814010$

Durán-Sánchez, C. A. (julio - diciembre de 2015). “Aspectos interventores en la participación política y electoral de jóvenes. Una reflexión sobre la información, interacción y difusión de contenidos en redes sociales para futuras". Desafios, 27(1), 47 - 81. Obtenido de http://www.redalyc.org/ articulo.oa? $\mathrm{id}=359638976003$

Fernández-Poncela, A. M. (septiembre de 1999). "Elecciones, Jóvenes y Política”. Convergencia. Revista de Ciencias Sociales, 6(20), 123 - 139. Obtenido de http://www.redalyc.org/articulo.oa?id=10502004

Jiménez-Morales, O. A. (marzo de 2015). "Los jóvenes y la democracia: retos y perspectivas para el ejercicio de su ciudadanía”. Tla-Melaua, 8(37), 30 - 49. Obtenido de http://www.scielo.org.mx/scielo.php?script=sci_ arttext\&pid=S1870-69162015000100030\&lang=es

Kropff, L. (enero - junio de 2011). "Debates sobre lo político entre jóvenes mapuche en Argentina". Revista Latinoamericana de Ciencias Sociales, Niñez y Juventud, 9(1), 83 - 99. Obtenido de http://www.redalyc.org/ articulo.oa? $\mathrm{id}=77320072003$

Leyva-Cordero, O., Muñiz, C., \& Flores Hernández, M. d. (julio - diciembre de 2016). La conformación de actitudes políticas de los jóvenes universitarios 
en el contexto preelectoral 2015 en Nuevo León. Revista Mexicana de Opinión Pública(21), 51 - 70. Obtenido de http://www.scielo.org.mx/ scielo.php?script=sci_arttext\&pid=S2448-49112016000200051\&lang=es

Mayorga, F. (abril de 2017). "Estado plurinacional y democracia intercultural en Bolivia”. Revista Brasileira de Ciencias Sociais, 32(94), 1 - 14. Obtenido de http://www.scielo.br/scielo.php?script=sci_arttext\&pid=S010269092017000200301\&lang=pt

Ramírez-Castro, J. (enero - junio de 2014). "Experiencias y expectativas en el debate político. Jóvenes de Manizales y elecciones". Revista Latinoamericana de Ciencias Sociales, Niñez y Juventud, 12(1), 243 - 256. Obtenido de http://www.redalyc.org/articulo.oa?id=77330034015

Reyes Kuri, J. F. (diciembre de 2009). "La inconstitucionalidad de algunas restricciones al derecho a ser elegido en Colombia". Revista Derecho del Estado, 23, 147 - 173. Obtenido de http://www.redalyc.org/articulo. oa? $\mathrm{id}=337630233006$

Rico-Revelo, D. (enero - junio de 2013). "Motivaciones de los jóvenes uninorteños para participar en elecciones locales y regionales en 2011". Revista de Derecho(39), 89 - 125. Obtenido de http://www.redalyc.org/ articulo.oa? $\mathrm{id}=85128616005$

Saez, V. (mayo de 2017). "El Derecho a ser Joven desde la Prensa Argentina". Educação \& Realidade, 1 - 18. Obtenido de http://www.scielo.br/scielo. php?script=sci_abstract\&pid=S2175-62362017005003106\&lng=en\&nrm $=$ iso\&tlng $=$ es

Silvestre Pineda, A. (noviembre de 2013). La participación política de los jóvenes: un nuevo reto para la democracia mexicana. Bien Comun, 19(224), 7 - 15. Obtenido de http://www.pan.org.mx/wp-content/uploads/ downloads/2013/12/BC224.pdf\#page=7 
Ugarte, C., Repáraz, C., \& Naval, C. (2013). “Participación y abstención de los jóvenes en las elecciones al Parlamento Europeo de 2009. Una respuesta desde la educación cívico-política". Educación XX1, 16(2), 209 - 229. Obtenido de http://www.redalyc.org/articulo.oa?id=70626451011

Wahren, J. (julio de 2016). “Acción colectiva y participación política de los jóvenes en el noroeste argentino. El caso de los "changos piqueteros de la UTD de Gral.Mosconi”.'Andes, 27(1).Obtenido dehttp://www.scielo.org.ar/ scielo.php?script=sci_arttext\&pid=S1668-80902016000100002\&lang=es

\section{Referencias normativas}

Constitución Política de la República (1998), Registro Oficial No. 01 de fecha 11 de agosto de 1998.

Constitución de la República (2008), Registro Oficial No. 442 de fecha 20 de octubre de 2008, con sus últimas enmiendas de fecha 21 de diciembre de 2015.

Convención Iberoamericana de Derechos de los Jóvenes (2008), publicada en el Registro Oficial No. 463 de fecha 10 de noviembre de 2008.

Ley de la Juventud (2001), publicada en el Registro Oficial No. 439 de fecha 24 de octubre de 2001, con sus últimas reformas de fecha 07 de julio de 2014.

Código de la Democracia (2009), publicada en el Registro Oficial Suplemento No. 578 de fecha 27 de abril de 2009, con sus últimas reformas de fecha 21 de enero de 2014. 